\title{
PERCURSOS, VIRTUALIDADE E PERCEPÇÕES AS POSSIBILIDADES DA IMAGINAÇÃO NA NARRATIVA DE SERGIO CHEJFEC
}

\section{Mariana Giordano UNR/CONICET}

RESUMO: A ideia do trabalho é apresentar situações descritas por Sergio Chejec em dois relatos: "El testigo" e "La experiência dramática". Ambas narrativas propõem uma maneira de traçar um mapa de um percurso. 0 foco não está em "escrever a cidade", mais o que interessa é a forma de nos imaginar nos percursos pela cidade. Como se coloca o narrador ante a história do flâneur benjaminianobaudelairiano do século XIX, e como e possível retomar essa perspectiva desde 0 anônimo atual que constitui o homem que passeia pelas grandes megalópoles de hoje. Fechamos 0 trabalho com reflexões que se encontram num texto que está no blog do escritor "Parábola anterior", que se chama Lo que viene después, onde propõe possibilidades para a literatura em relação à circulação e criação pela internet.

PALAVRAS-CHAVE: Sergio Chejfec. Narrativa. Percurso.

\section{TRAJECTORIES, POTENTIALITY AND PERCEPTIONS IMAGINATION POSSIBILITIES IN SERGIO CHEJFEC'S NARRATIVE}

ABSTRACT: The idea of this work is to present situations described on Sergio Chejfec's tales: "El testigo" and "La experiencia dramática". Both narratives propose one way to design a map to one trajectory. The focus is not in "write a city", but the important matter is a way to imagine travels through the city. The way the narrator is place in front of the history of the benjaminian-baudelairian flâneur of the $19^{\text {th }}$ century and how is possible to take this perspective from the "actual anonymous", in which the man who walk the big city today. The work finish with a reflection founded in a text that appear in the blog of the writer, "Parábola anterior", which name is Lo que viene después, where Sergio Cheifec propose possibilities for literature that have a relation with circulation and creation of internet.

KEYWORDS: Sergio Chejfec. Narrative. Trajectory.

é doutoranda em Humanidades e Artes da Universidad Nacional de Rosario com intercâmbio no doutorado em Humanidades da Pontifícia Universidade Católica do Rio de Janeiro. 


\title{
PERCURSOS, VIRTUALIDADE E PERCEPÇÕES AS POSSIBILIDADES DA IMAGINAÇÃO NA NARRATIVA DE SERGIO CHEJFEC
}

\author{
Mariana Giordano
}

Sergio Chejfec propõe formas bem diferenciadas de olhar Buenos Aires. Segundo as possibilidades e as relações que se pode ter com o mundo. Em nossa consideração é um escritor que está procurando a maneira de como sair para fora do mundo e estabelecer um diálogo entre sua literatura e as novas formas de subjetividades que surgem as relações propiciadas pelas novas tecnologias.

Neste sentido, El testigo (A testemunha $)^{1}$, o conto que trabalhamos, propõe imaginar um percurso pela Buenos Aires de 1939, quando Cortázar ainda morava em Buenos Aires. Pelo contrário, o romance La experiência dramática ${ }^{2}$ (A experiência dramática), escrito em 2012, faz referência a uma imaginação que só é possível com a chegada de internet e com suas possibilidades, como é a aplicação Google Maps.

Então, desde o texto de Georg Simmel As grandes cidades e a vida do espírito $^{3}$, quem imaginou a virada do século $X X$ e, Robin Régine, quem retoma a Walter Benjamin e o flâneur do século XIX no texto $L$ 'écriture flâneuse ${ }^{4}$, vamos na direção do presente junto com o texto de Michel de Certeau $A$ invenção do cotidiano ${ }^{5}$, mais também determinadas propostas de Nestor García Canclini, em Narrar o multiculturalismo ${ }^{6}$ e Jesús Martín Barbero em "Uma agenda para a mudança do século" do livro Oficio de cartógrafo. Travessias la-

${ }^{1}$ CHEJFEC, Sergio. El testigo; Lo que viene después. In: Parábola anterior, 2012. Todas as traduções são minhas.

2 Idem, La experiencia dramática. Buenos Aires: Alfaguara, 2012.

${ }^{3}$ SIMMEL, Georg. As grandes cidades e a vida do espírito. Mana, Rio de Janeiro, v. 11, n. 2, out. 2005.

${ }^{4}$ ROBIN, Régine. L'écriture flâneuse. In: Capitales de la modernité. Walter Benjamin et la ville. Paris: Éditions de l'éclat, 2005.

${ }^{5}$ CERTEAU, Michel de. A invenção do cotidiano. Org. Luce Giard e Pierre Mayol. Trad. Ephraim F. Alves. Petrópolis: Vozes, 1997.

${ }^{6}$ CANCLINI, Nestor García. Narrar o multiculturalismo. In: Consumidores e cidadãos. Conflitos culturais da globalização. Rio de Janeiro: Ed. UFRJ, 1995. 
tino-americanas da comunicação na cultura ${ }^{7}$, ajudam a traçar o percurso de leitura entre os dois textos. Para fazer mais visível a brecha temporal que vai desde as primeiras décadas do Século XX até começos do século XXI, recuperamos o texto de Renato Cordeiro Gomes, Janelas indiscretas e ruas devassadas: duas matrizes para a representação da cidade ${ }^{8}$, onde desarrolha ideias, as quais nos permitem desenrolar a leitura, contextualizando-as.

\title{
IMAGINAÇÃO DE PERCURSOS
}

El testigo é um conto, publicado no blog e no livro Modo linterna (Modo lanterna), que propõe um percurso por Buenos Aires a partir de um desenho feito com os endereços de escritores que moraram na capital Argentina. $O$ personagem chega a essa ideia pesquisando as velhas guias de telefone na Biblioteca Nacional.

\begin{abstract}
Samich está abocado a una etapa de verificación empírica. Lleva anotadas varias direcciones y va de un lado al otro de la ciudad. Camina cuando se trata de puntos cercanos o toma colectivos cuando son lejanos. Si uno lo ve, piensa en alguien absorbido por una actividad burocrática, o por lo menos una actividad hacia la que se siente obligado. En realidad, uno imagina que Samich busca reponer un mundo acotado de seres antiguos. ${ }^{9}$
\end{abstract}

Simmel deixa planteado o caráter intelectualista da vida anímica do habitante da grande cidade. O caráter blasé que protege dos perigos. Mais os escritores, imagina Samich, ainda intercambiam e habitam a cidade, saído do lugar comum de solidão no meio da multidão.

Para a época em que os endereços correspondiam aos escritores, Buenos Aires não era a mesma que conhecemos hoje. O transito, os engarrafamentos, a quantidade de automóveis (o grande sugestionador da modernidade) era bem mais divagar que hoje. Assim os escritores, morando numa das capitãs

\footnotetext{
${ }^{7}$ BARBERO, Jesús Martín. Uma agenda para a mudança do século. In: Oficio de cartógrafo. Travessias latino-americanas da comunicação na cultura. São Paulo: Loyola, 2004.

${ }^{8}$ GOMES, Renato Cordeiro. Janelas indiscretas e ruas devassadas: duas matrizes para a representação da cidade. Dispositiva, Belo Horizonte, v. 1, n. 1, 2012.

9 Samich está ocupado em uma etapa da verificação empírica. Leva vários endereços anotados e vai de um lado a outro da cidade. Caminha quando se trata de lugares próximos ou vai de ônibus quando são afastados. Se alguém o vê, pensa que está absorbido por uma atividade burocrática, o pelo menos uma atividade para a qual se sente obrigado. Na verdade, imaginase que Samich procura reconstruir um mundo apenas de seres antigos. CHEJFEC, Sergio. El testigo, op. cit.
} 
culturais do ocidente conseguiram ter uma forma de vida mais similar às das pequenas cidades, baseadas no ânimo e nas relações pautadas pelo sentimento.

Samich imagina um mundo já perimido onde o espirito subjetivo ainda era possível, mais, como afirma Simmel: "O desenvolvimento da cultura moderna caracteriza-se pela preponderância daquilo que se pode denominar espírito objetivo e o espírito subjetivo". ${ }^{10}$

Outra situação bem diferente é imaginada por Sergio Chejfec na La experiencia dramática. Ali começa a narração falando de que um pároco teve a intenção de compartilhar sua ideia de Deus. Para isso não teve melhor comparação que equiparar a Deus com o Google Maps. Como sempre se falou, Deus está em todas partes e com todo o mundo no momento todo, mais o difícil é fazer tangível a presença. Para voltar essa abstração numa coisa que é conhecida por quase todos, se não todos, os que estavam na missa, ele propõe imaginar a Deus como a nomeada aplicação da internet.

Hizo silencio y enseguida agregó que Dios es como los mapas en línea (dijo textualmente "Google Maps"). Puede observar desde arriba y desde los costados, es capaz de abarcar con la mirada un continente o enfocarse en una casa, hasta hacer zoom sobre el patio de una casa. ${ }^{11}$

Mais teve a delicadeza de pensar que Deus inclusive tinha mais "funções" que Google Maps, porque podia saber todo, além da representação visual com todas suas possibilidades: mapa, releve, trânsito, etc. Obviamente, como se fosse necessária a aclaração, sinalou que não significava que os mapas digitais fossem equivalentes a Deus.

O narrador, Félix, a partir dali, vai imaginando o percurso que ele faz para se encontrar com Rose, uma amiga dele com quem compartilham o gosto de falar. Então, ele imagina ao mesmo tempo que ele o faz, o trajeto concreto acompanhado com a imagem de Google Maps.

Temos que agregar a nova (2007) função de Street View, onde a partir de fotos, você pode caminhar pelas ruas. A montagem está feita por profissionais que reconstroem a vida pública. Como seu nome, a vista da rua é tirada

\footnotetext{
${ }^{10}$ SIMMEL, Georg. As grandes cidades e a vida do espírito, op. cit.

${ }^{11}$ Fez silêncio e em seguida falou que Deus é como os mapas na internet (disse textualmente "Google Maps"). Pode observar de cima e dos lados, é capaz de cobrir com seu olhar um continente ou concentrar-se em uma casa, até dar zoom no pátio de uma casa. CHEJFEC, Sergio. La experiencia dramática, op. cit., p. 9.
} 
da realidade. Só tem os rostos meios difusos para preservar a identidade das pessoas. Mais a ilusão ou sensação de estar caminhando as ruas é muito forte.

Esta representação por simulação, mostra o perfil de um mundo multifacetado que adota o ritmo dos pedestres, com uma lentidão típica da herança do flâneur que se nega a ingressar às leis do mercado e da vida produtiva.

Frente à loucura que governa as ruas cheias de engarrafamentos, os pedestres do século XXI, já não querem escrever a cidade como totalidade. $O$ objetivo é de ter seu próprio ritmo e seu próprio olhar, sempre parcial e provisório.

\section{DE ÓNIBUS, PEDESTRES E VIAGEIROS VIRTUAIS}

Nos anos 80, Michel de Certeau escreveu $A$ invenção do cotidiano. Redesenhar as práticas culturais no contexto das novas tecnologias, as artes de fazer, a cultura mesma constitui uma tarefa muito cara para os pensadores de hoje. Sabemos que o mundo das relações mudou de sentido e que o caráter anónimo dos fenómenos culturais mostra uma outra perspectiva dos vínculos que a arte pode estabelecer com a sociedade.

O homem ordinário se torna o narrador quando define o lugar do discurso e o espaço de seu desenvolvimento. O que quer dizer que já não é um privilégio dos artistas a invenção da narrativa desde uma ficcionalidade que os protege do cotidiano. Ao invés, o cotidiano é ficcional numa sociedade virtualizada.

A diferença temporal que separa as dois narrações escolhidas constitui exemplos de como se alterou nossa percepção ao longo do século XX e começos do século XXI. Hoje as guias telefónicas quase estão chegando ao fim, porque o telefone fixo é quase uma antiguidade. Aquele tempo onde se podia planejar uma cita a partir da data, o seja, o telefone e o endereço que aparecia na guia, já não é o tempo de hoje:

Samich imagina a Buenos Aires como una extensa colonia de escritores, el territorio temático donde intercambian números de teléfonos, comidas, fotografías y conversaciones. La ciudad vendría a ser el escenario, y como tal elemento central y a la vez accesorio. Podemos imaginar que Samich siente haber llegado 
tarde a la colonia, o intuye haber consultado fuentes demasiado atrasadas. ${ }^{12}$

A cidade é o herói da modernidade. Nesse sentido é normal que Samich imagine uma Buenos Aires ideal onde os escritores levam uma vida cultural ativa e compartilhada, baseada em encontros e trocas. Mais na verdade é só uma produção imaginaria desde um outro tempo. A moda do retro, do passado se impõe no pensamento do personagem ao ponto de fazê-lo deambular pelas ruas como um flâneur anacrónico.

Como bem imagina Michel de Certeau, tal vez as cidades se estejam deteriorando ao mesmo tempo que os procedimentos que as organizam. ${ }^{13}$ Assim na narrativa de La experiência dramática, escolhe a pedestres que constituem outra forma do tempo das percepções. Onde o traço vem substituir a prática: "(Certamente, os processos do caminhar podem reportar-se em mapas urbanos de maneira a transcrever lhes os traços (aqui densos, ali mais leves) e as trajetórias (passando por aqui e não por lá)". ${ }^{14}$

Certeau vão propor uma retórica caminhada ou enunciação pedestre para o ato de ir a pé que parece encontrar uma primeira definição como espaço de enunciação mais próximo a um presente descontínuo e fático, onde o paralelismo entre uma enunciação linguística e uma enunciação pedestre parece possível.

Com isso nos acercamos a narrativa de Chejfec onde moldar frases equivale a moldar percursos. A exterioridade e a interioridade se confundem, gerando elementos de coexistência, pois o espaço é um lugar praticado. ${ }^{15}$

Entre os séculos XV e XVII os mapas ganham autonomia e as descrições de percursos desaparecem. Hoje, no século XXI os mapas ajudam a criar descrições. De fato, a descrição é um ato criador que desenha uma forma performativa. Enquanto o relato abre um espaço para ações concretas.

E com a internet o espaço se faz mais amplo ainda. Não só tem relação com o espaço, mais bem, com o tempo. É verdade que se antes vivíamos em cidades, hoje vivemos na internet. O espaço virtual ganha lugar em nosso

\footnotetext{
${ }^{12}$ Samich imagina Buenos Aires como uma grande colônia de escritores, o território temático onde compartilham-se números de telefone, comidas, fotografias e conversas. A cidade se tornaria o cenário, e como tal, elemento central e, simultaneamente, acessório. Podemos imaginar que Samich sente ter chegado tarde na colônia, ou intui ter consultado fontes atrasadas demais. Idem, El testigo.

${ }^{13}$ CERTEAU, Michel de. A invenção do cotidiano, op. cit., p. 174.

${ }^{14}$ Ibidem, p. 176.

${ }^{15}$ Ibidem, p. 222.
} 
cotidiano de modo que nossa imaginação se situa tanto no espaço concreto como no espaço propiciado pela virtualidade.

O avance tecnológico possibilitou viajar, conhecer cidades enterais sem sair da própria casa. A janela se transformou em Windows. Essa cidade moderna que foi a testemunha do flâneur, e que olhava o desaparecimento do ser humano na massa, hoje virou num espaço anónimo onde a observação e a reflexão se misturam até não ser coisas separadas. Assim se pode caminhar tanto pelas ruas como pela tela.

Se pode desenhar o mesmo percurso e imaginar enquanto se caminha o traço na internet. O texto de Renato Cordeiro Gomes retoma o aporte de Julio Ramos, quem fala da retórica do passeio, com o sentido de que o caminhante sai de seu interior para estabelecer relações com a cidade desordenada.

E justamente, pela narrativa se pode organizar um percurso particular onde o individual vire anónimo. Ou seja, ali onde os relatos podem criar uma organização das ações no meio da cidade, é que se pode continuar pensando a cidade como espaço para narrar. Por isso, a enunciação pedestre proposta por Certeau, propõe uma estratégia discursiva.

A medida que se faz o percurso se organiza, ao mesmo tempo, a narração. E se associa um espaço aberto à operação de vagar sem destino. A ter imagens como se olhássemos um videoclipe, como propõe Canclini em seu texto Narrar o multiculturalismo, o seja, uma montagem de imagens descontínuas.

Os referentes de identidade se formam, agora, mais do que nas artes, na literatura e no folclore -que durante séculos produziram os signos de distinção das nações-, em relação com os repertórios textuais e iconográficos gerados pelos meios eletrônicos de comunicação e com a globalização da vida urbana. O que significam, dentro deste processo, as construções imaginárias que o contradizem. $^{16}$

A identidade é uma construção imaginaria que se narra, mais também, no mundo da tecnologia, pode ser uma imaginação no meio da solidão. E se a percepção não é compartilhada não se pode falar de identidade ao menos que seja possível que coexistam tantas identidades como habitantes tem o mundo.

Nesse sentido sublinhar o território pode ser uma estratégia para voltar as observações para o mundo. Faz sentido uma narrativa se poder ser lida, si não

${ }^{16}$ CANCLINI, Néstor García. Narrar o multiculturalismo, op. cit., p. 124. 
como se faz para ser parte da cultura? Assim, mapear a partir da casa dos escritores é uma possibilidade de fazer coexistir diferentes temporalidades numa mesma línea sincrónica.

Mais perto de nosso presente é o percurso desenhado por Félix em La experiencia dramática, onde se pensa e se percorre, ao mesmo tempo, no espaço concreto e no virtual. Os flashbacks e as conexões instantâneas estão presentes e se misturam gerando uma colagem pessoal e exterior: "Tudo é denso e fragmentário. Como nos vídeos, a cidade se fez de imagens saqueadas de todas as partes, em qualquer ordem. Para ser bom leitor da vida urbana, há que se dobrar ao ritmo e gozar das visões efêmeras." ${ }^{17}$

As narrações são necessárias. Faz parte do ser humano como forma de compartilhar a experiência. O primeiro mapa traçado na história o fez Penélope, tecendo e destecendo o tear, e simulando o percurso de Odisseu. Ele no espaço real, ela no espaço virtual. Assim explica Jesus Martín Barbero em seu texto "Uma agenda para a mudança do século".

A ideia metafórica do espaço virtual de Penélope, hoje é o mais cotidiano do mundo para a gente que tem aceso diário a internet. E a indiferenciada línea divisória entre o real e o virtual, em parte se deve a que nossa imaginação, nossa comunicação e nossa maneira de estar presente foi modificada pelas comunicações de massas: "A singularidade do mundo que habitamos passa pelos espaços virtuais que, em outros tempos, teciam os sonhos e as representações, e agora tecem também as redes da comunicação". ${ }^{18}$

A denominada tecnósfera reinventa um espaço comum mais próximo a nossas vivencias. As multiplicidades de temporalidades demostram o novo modo de habitar o mundo, de pensar os entornos artificias, mais também de imaginar a subjetividade que pode abrir horizontes desde o uso massivo e cotidiano dos meios tecnológicos.

No texto, Barbero explica como é que o desenvolvimento tecnológico transforma a imagem mental do mundo. Isto é o que acontece quando imaginamos, ao mesmo tempo que caminhamos pelas ruas, o traçado no Google Maps. Além do mais, as vezes acontece que primeiro conhecemos os lugares pelo mapa digital, então quando vamos com nosso corpo presente pelos espaços já vistos, lembramos as imagens e olhamos a partir delas.

\footnotetext{
17 Ibidem, p. 133.

${ }^{18}$ BARBERO, Jesús Martín. Uma agenda para a mudança do século, op. cit., p. 261.
} 
A biblioteca começa a ser o cemitério dos livros, enquanto no digital aparece uma faceta interativa da natureza humana. Chejfec se põe a imaginar no texto Lo que viene después ( $\mathrm{O}$ que vem depois) a literatura por vir. Se é possível que a literatura poda construir um leitor acorde a essas novas exigências de mutabilidade e instabilidade constantes. A ideia de simulação aparece quando reflexiona o que poderia acontecer com a literatura na era de internet, mais também com uma forma muito obvia de lidar com as novas tecnologias:

\begin{abstract}
También hay un aspecto muy evidente de lo digital que ejerce una fuerte presión sobre lo literario; me refiero a los protocolos técnicos, las marcas constructivas de los medios digitales extrapoladas a formatos literarios convencionales. Así, a veces se ven relatos epistolares construidos con base en mensajes electrónicos, o simulando entradas en twitter, etc. En esos encabezados reiterados, correspondientes a cada mensaje, podemos intuir la presencia excluyente de la máquina en tanto intermediario técnico. Son estrategias icónicas y un poco ingenuas desde un punto de vista, es cierto, y en su inocencia muestran también una pasividad poco crítica frente a estas metáforas técnicas, de quienes toman prestada su elocuencia, digamos, constructiva, y en este sentido son también poco naturalistas. ${ }^{19}$
\end{abstract}

A viagem que propõe nesse texto é uma simulação pelo virtual onde os percursos de outras viagens são recuperados, mas pelo Google Maps. O exemplo, neste caso é o livro de Agustín Fernández Mallo, "Mutaciones" pertencente ao El Hacedor (de Borges), remake, ali onde: "El narrador de Fernández Mallo se traslada junto con la pantalla, y en la pequeña mano blanca que representa la posición del cursor encuentra tanto un signo cultural como la cifra de su propia subjetividad de viajero" (Chejfec: Lo que viene después). (O narrador de Fernández Mallo é transferido junto com a tela, e na pequena mão branca que representa a posição do cursor encontra um signo cultural

\footnotetext{
${ }^{19}$ Também tem um aspecto muito evidente do digital que exerce uma forte pressão sobre o literário; quero dizer os protocolos técnicos, as marcas construtivas dos meios digitais extrapolados a formatos literários convencionais. Assim, as vezes se encontram relatos epistolares construídos com base em mensagens eletrônicas, ou simulando entradas em twitter, etc. Nestes cabeçalhos repetidos, correspondentes a cada mensagem, podemos sentir a presença excludente da máquina em tanto intermediário técnico. São estratégias icónicas e um pouco ingênuas desde um ponto de vista, na verdade, e em sua inocência mostram também uma passividade pouco crítica frente a estas metáforas técnicas, de quem tomam emprestado sua eloquência, digamos, construtiva, e nesse sentido são também pouco naturalistas. CHEJFEC, Sergio. Lo que viene después, op. cit.
} 
tanto como a sinal de sua própria subjetividade de viageiro).

Assim coloca fotografias tomadas com seu celular na tela do computador. O escritor recupera a viagem feito por Robert Smithson ${ }^{20}$ em seu ensaio Los monumentos de Passaic.

O interessante de discutir nessa publicação onde, a escrita antes mencionada, é questionada por María Kodama. Ela, a viúva de Borges, pediu a seus advogados retirar os exemplares não vendidos das livrarias por considerar um uso não permitido da obra de Borges. Quando Borges é uma das principais motivações de Fernández Mallo para fazer o experimento.

Isso me lembra o caso de Pablo Katchadjian, que em 2008 publica El Aleph engordado ( $O$ Aleph engordado), experimento onde suma mais de 5000 palavras ao conto de Borges. Nesta oportunidade a viúva também faz uma demanda judicial contra a propriedade intelectual.

Mas Borges parece ser o escritor indicado para tirar exemplos. Também Maria Kodama demandou ao cemitério de Genebra onde fica o túmulo de Borges ao ar livre porque enterraram a uma prostituta famosa perto de ele, o que ela considerou uma injuria.

Assim, como faz Fernández Mallo segundo Chejfec, põe à literatura em função de máquina que se somete as regras da simulação, consegui criar uma outra subjetividade de flâneur que repete um percurso pré-existente mais agora pela tela do computador. Mais só porque encontra na simulação um suporte para dar testemunha, para propor novas sensibilidades onde a subjetividade de hoje pode criar novas experiências.

Então, será uma nova forma de realismo como sugere Chejfec? "Realismo", palavra tão debatida nos tempos atuais. No texto de Renato Cordeiro Gomes, $O$ instante e o cotidiano urbano: um paradoxo de certo realismo literário e midiático ${ }^{21}$, se fala da importância das novas tecnologias e a relação com nossas percepções das cidades. O condicionamento que as novas imaginações que descobrimos a partir da internet insere em nosso olhar o mando, faz que a percepção mude junto com a paisagem.

Eu procuro ao escritor Fernández Mallo e é um físico. A física é nossa outra inspiração para ler o mundo. Quando a teoria e a crítica literária não são

${ }^{20}$ SMITHSON, Robert. Los monumentos de Passaic. In: Un recorrido por los monumentos de Passaic, Nueva Jersey. Barcelona: Gustavo Gili, 2009.

${ }^{21}$ GOMES, Renato Cordeiro. O instante e o cotidiano urbano: um paradoxo de certo realismo literário mediático. In: OLINTO, Heidrun Krieger; SCHØLLHAMMER, Karl Erik (Orgs.). Literatura e realidade(s). Rio de janeiro: Viveiro de Castro Editora, 2011. 
suficientes, procuramos uma leitura sobre a física teórica e o mundo começa a rolar novamente. Isso tem a ver com as potencialidades da literatura que propõe Sergio Chejfec, com as relações entre literatura e novas formas imaginarias do mundo de hoje. Assim as possibilidades de reflexão explodam em mil direções.

Então, voltamos ao escritor que cita Chejfec para falar das simulações digitais contemporâneas, ideal para refletir sobre a relação entre arte-ciência. Não vamos a desviar tanto o filo que estamos tentando seguir, mas se o mundo se pode pensar desde uma perspectiva hegeliana, o seja diacrónica, seria Aby Warburg quem há proposto pensar o mundo em seu sincronismo. Hegel corresponderia ao mundo de Newton, e Warburg ao mundo de Einstein.

Jesús Martín Barbero propõe o tempo cíclico para as origens, o tempo linear para a história cronológica, e o tempo esférico para o nosso presente. Hoje, as narrativas deveriam desrealizar o espaço, espalhar a memória e liberá-la da carga histórica.

O tempo é relativo e múltiplo. Ninguém mais fala de uma forma tão simples e contundente sobre o tempo como Borges. A história de múltiplos universos, já estava presente no conto El jardín de senderos que se bifurcan, onde se pode escolher todas as possibilidades juntas. Isso apareceu antes na literatura é depois virou o normal comportamento dos átomos. Então, será que são universos tão distantes a ciência e a arte? O forte caráter heurístico, até inclusive conjetural, da escrita dos físicos já é bem conhecida. E a revolta na arte pelo impacto tecnológico, também.

O mundo é probabilístico. O mundo seria um holograma. E a literatura é um objeto vivo também, que atravessa os tempos e que se redefine com cada novo olhar. Por isso, se busca de algum apoio para desenrolar uma abordagem que se adeque as expectativas. A possibilidade que Chejfec oferece no romance, La experiência dramática, e no exemplo de Fernández Mallo, é pensar o presente heterocrónicamente. Refletir com suas reflexões sobre essa mudança no centro das instituições que movem na literatura outras subjetividades. Félix está ali, experimentando com sua presença as mudanças, o vazio e a indiferença. 